\title{
The Real-World Observational Prospective Study of Health Outcomes with Dulaglutide and Liraglutide in Type 2 Diabetes Patients (TROPHIES): Baseline Patient-Reported Outcomes
}

\author{
Kristina S. Boye · Hélène Sapin · Luis-Emilio García-Pérez • \\ Myriam Rosilio · Marco Orsini Federici · Elke Heitmann • \\ Heike Jung • Ulrich Aigner • Bruno Guerci · Francesco Giorgino • \\ Kirsi Norrbacka
}

Received: June 5, 2020 / Published online: September 3, 2020

(C) The Author(s) 2020

\begin{abstract}
Introduction: Although patient-reported outcome (PRO) measures provide important information beyond clinical data, studies that assess the PROs of type 2 diabetes mellitus (T2DM) patients initiating injectable glucose-lowering medications in routine clinical practice are limited. We describe the perspectives of patients based on a diversified panel of generic and
\end{abstract}

Digital Features To view digital features for this article go to https://doi.org/10.6084/m9.figshare.12783287.

Electronic supplementary material The online version of this article (https://doi.org/10.1007/s13300020-00908-9) contains supplementary material, which is available to authorized users.

K. S. Boye $(\bowtie)$

Eli Lilly and Company, Indianapolis, IN, USA

e-mail: boye_kristina_secnik@lilly.com

H. Sapin · M. Rosilio

Lilly France SAS, Neuilly-sur-Seine, France

L.-E. García-Pérez

Lilly S.A., Alcobendas, Madrid, Spain

M. Orsini Federici

Eli Lilly and Company, Sesto Fiorentino, FI, Italy

E. Heitmann · H. Jung

Lilly Deutschland GmbH, Bad Homburg, Germany disease-specific PRO measures at the time of enrollment (baseline) in the TROPHIES study.

Methods: TROPHIES is a 24-month prospective observational study performed in France, Germany, and Italy in patients with T2DM who initiated their first injectable glucose-lowering medication with once-weekly dulaglutide or once-daily liraglutide. To better understand the perspectives of these patients regarding their overall health, treatment satisfaction, and quality of life and work, the patients' responses to the following questionnaires were collected at baseline before they initiated treatment with dulaglutide or liraglutide: EQ-5D-5L (scale: 0-1), EQ-VAS (visual analog scale: 0-100), Impact of Weight on Self-Perceptions Questionnaire (IWSP; scale: 0-100), Diabetes Treatment Satisfaction Questionnaire Status (DTSQs; scale: 0-36),

\author{
U. Aigner \\ Versdias GmbH, Sulzbach-Rosenberg, Germany \\ B. Guerci \\ University Hospital of Nancy, Vandoeuvre Lès \\ Nancy, France \\ F. Giorgino \\ University of Bari Aldo Moro, Bari, Italy \\ K. Norrbacka \\ Eli Lilly and Company, Helsinki, Finland
}


and Diabetes Productivity Measure (DPM; scale: 0-100). Analyses were descriptive in nature, with higher scores reflecting better outcomes.

Results: Data from patients at the time of enrollment were analyzed. At baseline, patients initiating dulaglutide $(N=1130)$ or liraglutide $(N=1051)$ rated their quality of life in terms of mean EQ-5D-5L index as 0.84 and 0.83 , and in terms of mean EQ-VAS as 67.5 and 67.5, respectively. The mean baseline scores in patients initiating dulaglutide or liraglutide were 59.8 and 61.3 for IW-SP, 24.6 and 25.8 for DTSQs, 78.6 and 79.5 for DPM Life Productivity, and 87.5 and 86.8 for DPM Work Productivity, respectively.

Conclusion: The information from this varied panel of PRO instruments collected at baseline complements clinical outcomes data.

Keywords: Dulaglutide; Glucagon-like peptide 1 receptor agonists; Liraglutide; Patientreported outcomes; Real-world study; Type 2 diabetes patients

\section{Key Summary Points}

Studies that assess the patient-reported outcomes (PROs) of persons with type 2 diabetes mellitus (T2DM) initiating injectable glucose-lowering medications in routine clinical practice are limited.

TROPHIES is a 24-month prospective observational study performed in France, Germany, and Italy in patients with T2DM who initiated their first injectable glucose-lowering medication with once-weekly dulaglutide or oncedaily liraglutide.

The perspectives of patients based on a diversified panel of generic and diseasespecific PRO measures at the time of study enrollment are described.
At baseline, patients initiating dulaglutide or liraglutide rated their quality of life and other health outcomes; the results corresponded to a mean EQ-5D-5L index of 0.84 and 0.83 , a mean EQ-VAS score of 67.5 and 67.5 , a mean IW-SP score of 59.8 and 61.3, a mean DTSQs score of 24.6 and 25.8, a mean DPM Life Productivity score of 78.6 and 79.5, and a mean DPM Work Productivity score of 87.5 and 86.8 , respectively.

In clinical practice, patients with T2DM who needed treatment intensification to improve glycemic control and were initiating their first injectable therapy with either dulaglutide or liraglutide generally reported similar quality of life ratings.

The information from this varied panel of PRO instruments in a real-world setting complements clinical outcomes data.

\section{DIGITAL FEATURES}

This article is published with digital features to facilitate understanding of the article. You can access the digital features on the article's associated Figshare page. To view digital features for this article go to https://doi.org/10.6084/m9. figshare.12783287.

\section{INTRODUCTION}

The management of type 2 diabetes mellitus (T2DM) through diet, lifestyle, and medication has consequences for the patient's quality of life. With the growing number and types of glucose-lowering medications (GLMs), choosing an appropriate T2DM medication can complicate management and represent a burden for patients $[1,2]$. T2DM is a progressive disease and maintaining glycemic control over time often requires treatment intensification by switching to injectable therapy. Glucagon-like peptide-1 receptor agonists (GLP-1 RAs) are typically the first injectable therapy 
recommended for T2DM, as they offer improved glycemic control and other health benefits [1-3]. Dulaglutide (Trulicity ${ }^{\circledR}$, Eli Lilly and Company, USA; approved in the European Union in 2014) and liraglutide (Victoza ${ }^{\circledR}$, Novo Nordisk, Denmark; approved in the European Union in 2010) are injectable GLP-1 RAs approved for T2DM treatment, and both are associated with positive clinical outcomes [4-9].

Collected real-world evidence can complement randomized clinical trials, providing, for example, longer-term data on treatment trends, patient adherence, durability of clinical outcomes, and economic data, all of which are fundamental for healthcare decision makers. Real-world studies involving patients commencing their first injectable therapy with dulaglutide or liraglutide can help us to understand the impact of prescribing GLP-1 RAs on T2DM clinical outcomes in routine practice. Patient-reported outcome (PRO) measures can complement clinical outcomes and, beyond efficacy and safety data, enrich our understanding of the patients' perspective of GLP-1 RA use in routine clinical practice $[10,11]$.

Although PROs for patients taking dulaglutide and liraglutide have previously been reported in clinical trials, real-world evidence is limited [11-17]. We studied the use of these GLMs in a single prospective observational study, thereby addressing the need for additional real-world evidence. One of the objectives of the study (TROPHIES; The Real-world Observational Prospective study of Health outcomes with dulaglutIde and liraglutide in type 2 diabeteS patients) is to assess PROs regarding overall quality of life, treatment satisfaction, and productivity in patients initiating their first GLP-1 RA injectable-either dulaglutide or liraglutide-as part of T2DM therapy. At the commencement of the study, dulaglutide and liraglutide were the most prominently used GLP-1 RAs in many European countries. Clinical information at baseline has been presented previously $[18,19]$. This paper focuses on the responses to the PRO questionnaires collected at the time of patient enrollment, providing descriptive information on patient populations initiating dulaglutide or liraglutide as the first GLP-1 RA treatment.

\section{METHODS}

\section{Patients and Study Design}

TROPHIES is a 24-month prospective observational study conducted in two cohorts of T2DM patients initiating injectable GLP-1 RA treatment with dulaglutide or liraglutide. Male or female patients aged $\geq 18$ years were eligible to participate if they were naive to injectable treatment and were scheduled to begin their first injectable antihyperglycemic treatment with either dulaglutide once weekly or liraglutide once daily according to the approved label and at the discretion of the diabetes health care provider in the respective country. The patients were enrolled from three European countries: France, Germany, and Italy. Data were collected at baseline and will continue to be collected at routine clinical care visits approximately $6,12,18$, and 24 months after initiating GLP-1 RA treatment (Fig. S1 in the Electronic supplementary material, ESM).

\section{Study Outcomes}

The primary objective of the TROPHIES study is to estimate the time spent on the first GLP-1 RA (initiated at baseline) without a significant treatment change (time to first significant treatment change) due to treatment- or diabetes-related factors. One of the secondary objectives of the TROPHIES study is to describe the PROs associated with the treatment of diabetes with dulaglutide or liraglutide, including health-related quality of life (HR-QoL), treatment satisfaction, and productivity.

\section{Study Procedures and Data Management}

Dulaglutide and liraglutide are subcutaneously administered as directed by the respective Summary of Product Characteristics [20, 21]. The recommended dose for dulaglutide is $0.75 \mathrm{mg}$ once weekly as monotherapy and $1.5 \mathrm{mg}$ once weekly when used as add-on therapy. The $0.75 \mathrm{mg}$ once-weekly dose can be considered a starting dose in add-on therapy for potentially vulnerable populations. The 
liraglutide starting dose is $0.6 \mathrm{mg}$ per day. After at least one week, the liraglutide dose is increased to $1.2 \mathrm{mg}$ per day. This can be further increased to $1.8 \mathrm{mg}$ for patients that are expected to benefit from a dose increase, and based on the clinical response.

At the first study visit, information was collected from participating patients and from their medical records over the previous 6-month period. This information included demographic data, clinical history (including diabetes duration, previous glycated hemoglobin (HbA1c) level, concomitant diseases, previous treatment, and non-antihyperglycemic medications). Data on resource use for diabetes during the last 6 months were also collected. Electronic case report forms were used for data entry. The HR-QoL and other PRO instruments described in the following sections were administered and completed via paper questionnaires during the first study visit, prior to initiating treatment with dulaglutide or liraglutide.

\section{PRO Measures}

Five PRO measures were administered at baseline and at each postbaseline visit (Table 1). These included the Diabetes Treatment Satisfaction Questionnaire Status (DTSQs) [22, 23], EQ-5D-5L and the EQ-5D Visual Analog Scale (EQ-VAS) [24, 25], the Impact of Weight on SelfPerceptions Questionnaire (IW-SP) [26], and the Diabetes Productivity Measure (DPM) [27].

DTSQs is used to evaluate satisfaction with diabetes treatment regimens, as well as concerns about hyperglycemia and hypoglycemia $[22,23]$. Six items are measured (satisfied with current treatment; feel convenient about recent treatment; feel flexible about recent treatment; satisfied with diabetes understanding; recommend present treatment to others; continue with present treatment) and summed to provide a treatment satisfaction score on a scale of $0-36$. Higher scores indicate greater satisfaction. Two items concerning times of unacceptably high and low blood glucose are rated from 0 (none of the time) to 6 (most of the time). These items are scored separately from the six treatment satisfaction items and from each other. Here, lower scores indicate blood glucose levels closer to the ideal and higher scores indicate problems with blood glucose levels.

The EQ-5D-5L is a descriptive instrument that is used to measure overall health status [25]. A weighted summary index score is derived for five dimensions (mobility; self-care; usual activities; pain/discomfort; and anxiety/depression), with each dimension having five response levels $(1=$ no problems; $2=$ slight problems; $3=$ moderate problems; $4=$ severe problems; $5=$ unable to/extreme problems). The index score is reported on a scale 0 to 1 , whereby a score of 1 indicates perfect health, 0 indicates death, and negative scores represent states that are worse than death. The EQ-VAS is completed in conjunction with the EQ-5D-5L and allows patients to self-rate their health status on a scale of 0 to 100 , where 0 is the worst imaginable health and 100 is the best imaginable health state.

The IW-SP questionnaire is designed to assess the patients' self-perception relating to their body weight [26]. Three items are measured (feel unhappy with appearance due to weight; feel self-conscious in public due to weight; feel unhappy due to comparing weight with others) on a 5-point scale ranging from 1 (always) to 5 (never). The raw scores are averaged and linearly transformed to produce a measure from 0 to 100. Higher raw scores and higher transformed scores correspond to better self-perception in relation to one's weight.

The DPM assesses life and work productivity impairments associated with diabetes [27]. The Life Productivity domain contains nine items (prevented from accomplishing important things; prevented from concentrating; interferes with ability to accomplish daily activities; takes longer than necessary to complete tasks; have trouble getting up and being active in the morning; have to limit your daily activities; accomplish less than would like to; too tired to accomplish as much as would like to; low blood sugar symptoms interfere with ability to perform daily activities). This domain is followed by the Work Productivity domain, which includes five items (difficulty performing work duties; difficulty controlling emotions with 
Table 1 Overview of the PRO measures administered at baseline in the TROPHIES study

\begin{tabular}{|c|c|c|c|c|}
\hline Questionnaire & $\begin{array}{l}\text { Number of items/dimensions } \\
\text { (concept) }\end{array}$ & Scale & Score range & $\begin{array}{l}\text { Score } \\
\text { interpretation }\end{array}$ \\
\hline \multirow[t]{3}{*}{$\begin{array}{l}\text { Diabetes Treatment } \\
\text { Satisfaction } \\
\text { Questionnaire } \\
\text { Status (DTSQs) } \\
\text { [22] }\end{array}$} & $\begin{array}{l}6 \text { items (satisfaction; convenience; } \\
\text { flexibility; understanding; likely to } \\
\text { recommend; continuation) }\end{array}$ & $\begin{array}{l}7 \text { points, } \\
0 \text { "very } \\
\text { dissatisfied", } \\
\text { "inconvenient", } \\
\text { etc. to } \\
6 \text { "very satisfied", } \\
\text { "convenient", } \\
\text { etc. }\end{array}$ & $0-36$ & $\begin{array}{l}\text { Higher scores } \\
\text { indicate greater } \\
\text { satisfaction }\end{array}$ \\
\hline & 1 item (hyperglycemia) & $\begin{array}{l}7 \text { points, } \\
0 \text { "none of the } \\
\text { time" to } \\
6 \text { "most of the } \\
\text { time" }\end{array}$ & $0-6$ & $\begin{array}{l}\text { Lower scores } \\
\text { indicate blood } \\
\text { glucose levels } \\
\text { closer to ideal }\end{array}$ \\
\hline & 1 item (hypoglycemia) & $\begin{array}{l}7 \text { points, } \\
0 \text { "none of the } \\
\text { time" to } \\
6 \text { "most of the } \\
\text { time" }\end{array}$ & $0-6$ & $\begin{array}{l}\text { Lower scores } \\
\text { indicate blood } \\
\text { glucose levels } \\
\text { closer to ideal }\end{array}$ \\
\hline \multirow[t]{2}{*}{ EQ-5D-5L [25] } & $\begin{array}{l}5 \text { dimensions (mobility; self-care; usual } \\
\text { activities; pain/discomfort; anxiety/ } \\
\text { depression) }\end{array}$ & $\begin{array}{l}5 \text { levels, } \\
1 \text { "no problem" } \\
\text { to } \\
5 \text { "unable to/ } \\
\text { extreme } \\
\text { problems" }\end{array}$ & $\begin{array}{c}0-1 \text { (weighted } \\
\text { index score)* }\end{array}$ & $\begin{array}{l}\text { Higher scores } \\
\text { indicate higher } \\
\text { health utility }\end{array}$ \\
\hline & 1 item (visual analog scale) & $\begin{array}{l}- \\
0 \text { "worst } \\
\text { imaginable } \\
\text { health" to } \\
100 \text { "best } \\
\text { imaginable } \\
\text { health" }\end{array}$ & $0-100$ & $\begin{array}{l}\text { Higher scores } \\
\text { indicate better } \\
\text { imaginable health }\end{array}$ \\
\hline $\begin{array}{l}\text { Impact of Weight on } \\
\text { Self-Perceptions } \\
\text { Questionnaire } \\
\text { (IW-SP) [26] }\end{array}$ & $\begin{array}{l}3 \text { items (unhappy due to appearance; } \\
\text { self-conscious comparing to others; } \\
\text { unhappy comparing to others) }\end{array}$ & $\begin{array}{l}5 \text { points, } \\
1 \text { "always" to } \\
5 \text { "never" }\end{array}$ & $\begin{array}{l}0-100 \\
\quad(\text { transformed })\end{array}$ & $\begin{array}{l}\text { Higher scores } \\
\text { indicate better } \\
\text { self-perception }\end{array}$ \\
\hline
\end{tabular}


Table 1 continued

\begin{tabular}{|c|c|c|c|c|}
\hline Questionnaire & $\begin{array}{l}\text { Number of items/dimensions } \\
\text { (concept) }\end{array}$ & Scale & Score range & $\begin{array}{l}\text { Score } \\
\text { interpretation }\end{array}$ \\
\hline \multirow[t]{4}{*}{$\begin{array}{l}\text { Diabetes Productivity } \\
\text { Measure (DPM) } \\
{[27]}\end{array}$} & $\begin{array}{l}1 \text { dimension (life); } 9 \text { items } \\
\text { (accomplishing things; } \\
\text { concentrating; daily activities; tasks; } \\
\text { active; limits; accomplish less; tired; } \\
\text { hypoglycemia symptoms) }\end{array}$ & $\begin{array}{l}5 \text { points, } \\
100 \text { "never" to } \\
0 \text { "always" }\end{array}$ & $\begin{array}{l}0-100 \\
\quad(\text { transformed })\end{array}$ & $\begin{array}{l}\text { Higher scores } \\
\text { indicate higher } \\
\text { productivity }\end{array}$ \\
\hline & $\begin{array}{l}1 \text { dimension (work); } 5 \text { items } \\
\text { (performing; emotions; productive; } \\
\text { miss work; reschedule) }\end{array}$ & $\begin{array}{l}5 \text { points, } \\
100 \text { "never" to } \\
0 \text { "always" }\end{array}$ & $\begin{array}{l}0-100 \\
\quad(\text { transformed })\end{array}$ & $\begin{array}{l}\text { Higher scores } \\
\text { indicate higher } \\
\text { productivity }\end{array}$ \\
\hline & 1 item (short-term goals) & $\begin{array}{l}5 \text { points, } \\
100 \text { "not at all" to } \\
0 \text { "extremely" }\end{array}$ & $0-100$ & $\begin{array}{l}\text { Higher scores } \\
\text { indicate less } \\
\text { problems } \\
\text { reaching short- } \\
\text { term goals }\end{array}$ \\
\hline & 1 item (long-term goals) & $\begin{array}{l}5 \text { points, } \\
100 \text { "not at all" to } \\
0 \text { "extremely" }\end{array}$ & $0-100$ & $\begin{array}{l}\text { Higher scores } \\
\text { indicate less } \\
\text { problems } \\
\text { reaching long- } \\
\text { term goals }\end{array}$ \\
\hline
\end{tabular}

${ }^{*}$ A score of 1 indicates perfect health, 0 indicates death, and negative scores represent values as worse than death

coworkers; feel less productive at work; miss work; need to reschedule meetings). All fourteen items are measured on a 5-point scale from 100 (never) to 0 (always). The scores are transformed on a 0 - to 100-point scale, with higher scores indicating greater productivity. Two standalone "nonvalidated" items measuring short-term and long-term goals are included in the DPM and are reported separately. These items are on a 5-point scale from 100 (not at all) to 0 (extremely). Similarly, higher scores correspond to higher perceived life productivity.

\section{Sample Size and Statistical Measures}

The sample size of 350 patients per cohort in each country was deemed to be sufficient to provide a satisfactory estimate of the time until a significant treatment change occurred. This sample size was considered large enough to permit separate evaluations of patients initiating dulaglutide at the recommended $1.5 \mathrm{mg}$ dose, to allow descriptive analyses of patients on the lower $0.75 \mathrm{mg}$ dose, and to similarly assess the two liraglutide doses $(1.2 \mathrm{mg}$ and $1.8 \mathrm{mg}$ ).

Patients were described by treatment cohort (dulaglutide or liraglutide). Analysis was performed for the overall population (all countries pooled) and by each country. Absolute and relative frequencies were used to describe categorical variables. Descriptive summary statistics were presented for continuous variables, including number of patients, number of patients with missing data, mean \pm standard deviation (SD), median quartiles, minimum values, and maximum values. PROs were scored according to the developer's guidelines. Due to 
Table 2 Baseline demographic and clinical characteristics of patients initiating dulaglutide or liraglutide

\begin{tabular}{|c|c|c|c|}
\hline Characteristics & $\begin{array}{l}\text { Dulaglutide } \\
N=1130\end{array}$ & $\begin{array}{l}\text { Liraglutide } \\
N=1051\end{array}$ & ${ }^{*} p$-value \\
\hline \multicolumn{4}{|l|}{ Demographic information, mean (SD) } \\
\hline Age (years) & $58.92(11.01)$ & $59.45(10.98)$ & 0.253 \\
\hline Male $[n(\%)]$ & $623(55.1)$ & $601(57.2)$ & 0.335 \\
\hline BMI $\left(\mathrm{kg} / \mathrm{m}^{2}\right)$ & $33.70(6.58)$ & $34.12(6.53)$ & 0.147 \\
\hline Weight $(\mathrm{kg})$ & $96.03(21.62)$ & $97.35(21.38)$ & 0.165 \\
\hline Duration of T2DM, mean (SD) (years) & $8.58(6.89)$ & $8.36(6.93)$ & 0.476 \\
\hline \multicolumn{4}{|l|}{$\mathrm{HbA}_{1 \mathrm{c}}$, mean $(\mathrm{SD})$} \\
\hline$n$ & 1102 & 1032 & \\
\hline$\%$ & $8.19(1.19)$ & $8.29(1.33)$ & 0.059 \\
\hline $\mathrm{mmol} / \mathrm{mol}$ & $66.00(13.01)$ & $67.10(14.54)$ & \\
\hline \multicolumn{4}{|l|}{ Reported $\mathrm{HbA}_{1 \mathrm{c}}$ target, mean $(\mathrm{SD})$} \\
\hline$n$ & 1125 & 1046 & \\
\hline$\%$ & $6.87(0.38)$ & $6.85(0.36)$ & 0.358 \\
\hline $\mathrm{mmol} / \mathrm{mol}$ & $51.57(4.15)$ & $51.36(3.94)$ & \\
\hline \multicolumn{4}{|l|}{$\begin{array}{c}\text { Difference between } \mathrm{HbA}_{1 \mathrm{c}} \text { levels at } \\
\text { baseline and target, mean }(\mathrm{SD})\end{array}$} \\
\hline$n$ & 1102 & 1032 & \\
\hline$\%$ & $1.32(1.12)$ & $1.44(1.27)$ & 0.017 \\
\hline $\mathrm{mmol} / \mathrm{mol}$ & $9.09(12.24)$ & $7.78(13.88)$ & \\
\hline \multicolumn{4}{|l|}{ Number of oral medication classes } \\
\hline$n$ & 1130 & 1051 & \\
\hline 0 & $160(14.2)$ & $149(14.2)$ & - \\
\hline 1 & $642(56.8)$ & $590(56.1)$ & - \\
\hline 2 & $297(26.3)$ & $277(26.4)$ & - \\
\hline 3 & $30(2.7)$ & $34(3.2)$ & - \\
\hline \multicolumn{4}{|l|}{ Diabetes-related medical conditions, $n(\%)$} \\
\hline$n$ & 1121 & 1046 & \\
\hline Patients with at least 1 macrovascular condition ${ }^{\mathrm{a}, * *}$ & $160(14.2)$ & $257(24.5)$ & $<0.001$ \\
\hline Patients with at least 1 microvascular condition ${ }^{\mathrm{b}, * *}$ & $228(20.2)$ & $199(18.9)$ & 0.442 \\
\hline
\end{tabular}


Table 2 continued

\begin{tabular}{llll}
\hline Characteristics & $\begin{array}{l}\text { Dulaglutide } \\
\boldsymbol{N}=\mathbf{1 1 3 0}\end{array}$ & $\begin{array}{l}\text { Liraglutide } \\
\boldsymbol{N}=\mathbf{1 0 5 1}\end{array}$ & ${ }^{*} \boldsymbol{p}$-value \\
\hline Other diagnoses, $n(\%)$ & 1121 & 1046 & \\
$n$ & $719(63.6)$ & $665(63.3)$ & - \\
Patients with hyperlipidemia ${ }^{* *}$ & $813(71.9)$ & $783(74.5)$ & - \\
Patients with hypertension $^{* *}$ & & & \\
\hline
\end{tabular}

$B M I$ body mass index, HbAlc glycated hemoglobin, $N$ total population size, $n$ number of patients, $S D$ standard deviation, T2DM type 2 diabetes mellitus

a Includes patients with cerebrovascular disease; congestive heart failure; dementia; hemiplegia or paraplegia; myocardial infarction; and peripheral vascular disease at baseline

b Includes patients with macroalbuminuria; microalbuminuria; nephropathy; neuropathy; and retinopathy at baseline

${ }^{*} p$ values for treatment effect were computed using the $\chi^{2}$ test for categorical and the $T$ test for continuous variables. ${ }^{* *}$ These percentages were calculated based on the overall population, as not all patients completed all of the forms

questionnaires not being completed, the sample sizes for each PRO varied and were less than the clinical data. The study protocol was approved by local institutional review boards, and all patients provided written informed consent. The study is executed in accordance with the Declaration of Helsinki 1964 and its later amendments and Guideline on Good Clinical Practices as well as country-specific requirements [28]. Eli Lilly \& Company received approval to carry out the study at each study site before study initiation.

\section{RESULTS}

\section{Patients and Disease Characteristics at Baseline}

In the TROPHIES study, 2181 patients were prescribed dulaglutide $(N=1130$, mean (SD) 59 (11) years, $55 \%$ male) or liraglutide $(N=1051$, 59 (11) years, 57\% male) and were eligible for baseline clinical analysis (Table 2). The baseline demographics, clinical characteristics, and concomitant medication use were similar across patient cohorts. In both cohorts, the mean HbA1c levels at baseline exceeded the glycemic control targets reported by physicians in the study as their treatment objective. The mean difference between the baseline and target
HbA1c values was statistically significantly different between the two cohorts $(p=0.017)$, with patients starting liraglutide further from the HbA1c goal at the start of treatment. In both cohorts, most of the patients had a difference between the baseline and target HbA1c levels of $\geq 1 \%$. Around $86 \%$ of the patients were already receiving at least one oral GLM at the time of enrollment.

Diabetes-related conditions varied across patient cohorts (Table 2) [18]. The number of patients who had a macrovascular condition in the liraglutide cohort (25\%) was significantly higher $(p<0.001)$ than the corresponding number in the dulaglutide (14\%) cohort. There was no significant difference between the dulaglutide (20\%) and liraglutide (19\%) cohorts in the number of patients with at least one microvascular condition. The majority of patients had hyperlipidemia and hypertension.

\section{PRO Measures}

Treatment satisfaction was analyzed in a total of 2088 patients (Table 3). At baseline, patient satisfaction with the current treatment (before initiating dulaglutide or liraglutide) was similar for both cohorts. The overall mean (SD) DTSQs score was 25.17 (7.79), with patients initiating dulaglutide having lower satisfaction with 
Table 3 Mean patient-reported outcomes at baseline

\begin{tabular}{|c|c|c|c|c|}
\hline Characteristics & Dulaglutide & Liraglutide & Total & ${ }^{*} p$ value \\
\hline \multicolumn{5}{|l|}{ DTSQs } \\
\hline$n$ & 1094 & 994 & 2088 & \\
\hline Mean & $24.63(8.03)$ & $25.76(7.46)$ & $25.17(7.79)$ & $<0.001$ \\
\hline $\operatorname{Median}(\min / \max )$ & $26.00(0.00 / 36.00)$ & $27.00(0.00 / 36.00)$ & $26.00(0.00 / 36.00)$ & \\
\hline 25th/75th percentile & $18.00 / 31.00$ & $20.00 / 32.00$ & $19.00 / 32.00$ & \\
\hline \multicolumn{5}{|l|}{ DTSQs Hyperglycemia } \\
\hline$n$ & 1096 & 995 & 2091 & \\
\hline Mean & $3.28(1.88)$ & $3.32(1.93)$ & $3.30(1.90)$ & 0.675 \\
\hline Median $(\min / \max )$ & $3.00(0.00 / 6.00)$ & $4.00(0.00 / 6.00)$ & $4.00(0.00 / 6.00)$ & \\
\hline 25 th/75th percentile & $2.00 / 5.00$ & $2.00 / 5.00$ & $2.00 / 5.00$ & \\
\hline \multicolumn{5}{|l|}{ DTSQs Hypoglycemia } \\
\hline$n$ & 1095 & 995 & 2090 & \\
\hline Mean & $1.37(1.70)$ & $1.35(1.69)$ & $1.36(1.69)$ & 0.769 \\
\hline Median $(\min / \max )$ & $1.00(0.00 / 6.00)$ & $1.00(0.00 / 6.00)$ & $1.00(0.00 / 6.00)$ & \\
\hline 25 th/75th percentile & $0.00 / 3.00$ & $0.00 / 3.00$ & $0.00 / 3.00$ & \\
\hline \multicolumn{5}{|l|}{ EQ-5D-5L } \\
\hline$n$ & 1103 & 1018 & 2121 & \\
\hline Mean & $0.84(0.21)$ & $0.83(0.23)$ & $0.83(0.22)$ & 0.230 \\
\hline Median $(\min / \max )$ & $0.91(-0.38 / 1.00)$ & $0.91(-0.49 / 1.00)$ & $0.91(-0.49 / 1.00)$ & \\
\hline 25th/75th percentile & $0.81 / 0.97$ & $0.80 / 0.97$ & $0.80 / 0.97$ & \\
\hline \multicolumn{5}{|l|}{ EQ-VAS } \\
\hline$n$ & 1102 & 1017 & 2119 & \\
\hline Mean & $67.53(19.74)$ & $67.49(17.90)$ & $67.51(18.88)$ & 0.964 \\
\hline Median $(\min / \max )$ & $70.00(0.00 / 100.00)$ & $70.00(0.00 / 100.00)$ & $70.00(0.00 / 100.00)$ & \\
\hline 25th/75th percentile & $50.00 / 80.00$ & $55.00 / 80.00$ & $50.00 / 80.00$ & \\
\hline \multicolumn{5}{|l|}{ IW-SP } \\
\hline$n$ & 1098 & 1010 & 2108 & \\
\hline Mean & $59.83(31.27)$ & $61.33(30.50)$ & $60.55(30.90)$ & 0.266 \\
\hline Median $(\min / \max )$ & $66.67(0.00 / 100.00)$ & $66.67(0.00 / 100.00)$ & $66.67(0.00 / 100.00)$ & \\
\hline 25th/75th percentile & $33.33 / 83.33$ & $41.67 / 91.67$ & $37.50 / 83.33$ & \\
\hline \multicolumn{5}{|c|}{ DPM Life Productivity score } \\
\hline$n$ & 1103 & 1011 & 2114 & \\
\hline Mean & $78.58(22.75)$ & $79.51(21.61)$ & $79.03(22.21)$ & 0.340 \\
\hline
\end{tabular}


Table 3 continued

\begin{tabular}{lllll}
\hline Characteristics & Dulaglutide & Liraglutide & Total & ${ }^{*}$ value \\
\hline Median (min/max) & $86.11(0.00 / 100.00)$ & $86.11(8.33 / 100.00)$ & $86.11(0.00 / 100.00)$ & \\
25th/75th percentile & $66.67 / 97.22$ & $66.67 / 97.22$ & $66.67 / 97.22$ & \\
DPM Work Productivity score & & & \\
$n$ & 731 & 561 & 1292 & \\
Mean & $87.45(18.11)$ & $86.84(17.35)$ & $87.19(17.78)$ & 0.540 \\
Median (min/max) & $95.00(0.00 / 100.00)$ & $95.00(15.00 / 100.00)$ & $95.00(0.00 / 100.00)$ & \\
25th/75th percentile & $80.00 / 100.00$ & $80.00 / 100.00$ & $80.00 / 100.00$ & \\
\hline
\end{tabular}

Data are given as mean $(\mathrm{SD})$

DPM Diabetes Productivity Measure, DTSQs Diabetes Treatment Satisfaction Questionnaire Status, IW-SP Impact of Weight on Self-Perceptions Questionnaire, $N$ total population size, $n$ number of patients who were in the PRO population and answered this questionnaire at this visit, $S D$ standard deviation

${ }^{*} p$ values for treatment effect were computed using the $\chi^{2}$ test for categorical and the $T$ test for continuous variables

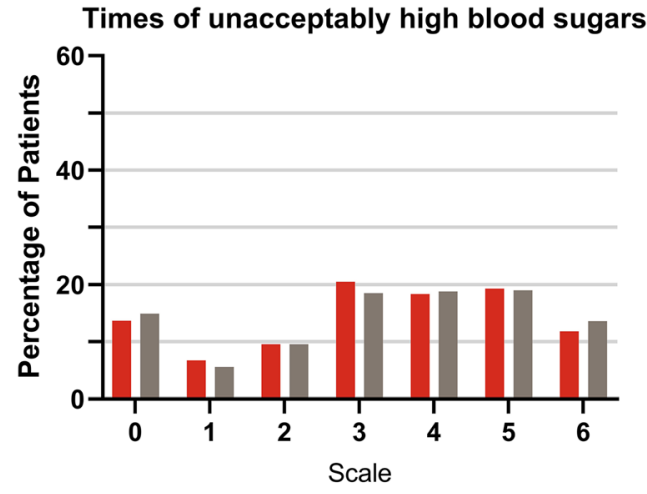

Number of patients: $\begin{array}{lc}\text { Dulaglutide } & 1096 \\ & 995\end{array}$

Fig. 1 Results of DTSQs items concerning times of unacceptably high and low blood glucose at baseline. The proportions of patients reporting unacceptably low and/or high blood sugars rated from 0 (none of the time) to 6

current treatment $(p<0.001)$. In the TROPHIES study, data on the patients who perceived hyperglycemic and/or hypoglycemic episodes were also collected using the DTSQs questionnaire. Around $14 \%$ of patients reported no unacceptably high blood sugars, and around $50 \%$ of patients reported no unacceptably low blood sugars (Fig. 1). The perceived frequency of

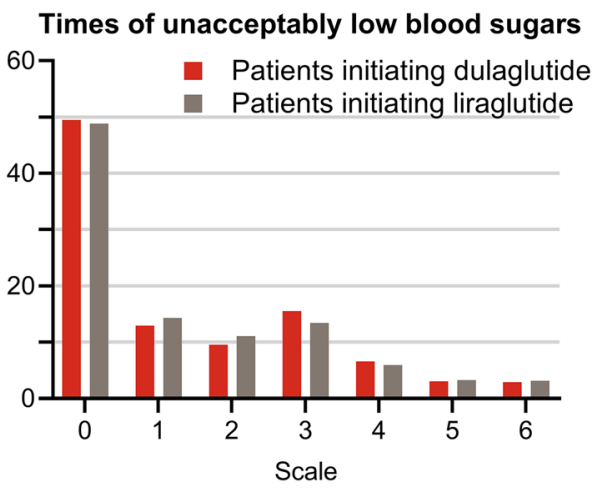

1095

995

(most of the time) are shown. The number of patients who, at this visit, were in the PRO population and answered at least one question on this questionnaire is given

unacceptably high blood sugars [mean (SD) 3.30 (1.90)] was greater than the perceived frequency of unacceptably low blood sugars [mean (SD) 1.36 (1.69)] (Table 3). Around 70\% of patients perceived experiencing three or more hyperglycemic episodes (Fig. 1).

The EQ-5D-5L and the EQ-VAS questionnaires were completed by 2121 and 2119 

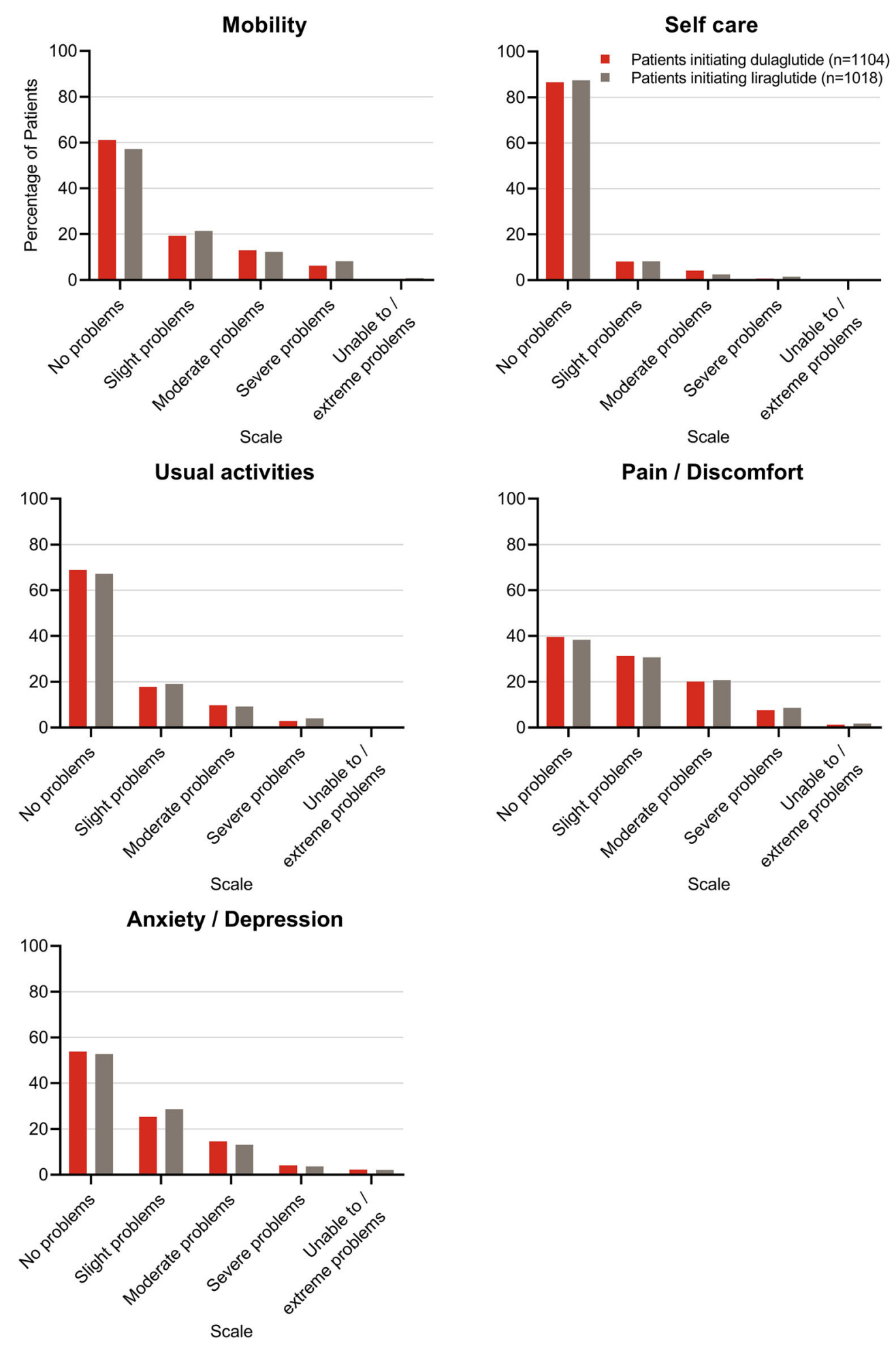

Fig. 2 Baseline results of the EQ-5D-5L quality of life questionnaire by dimension. The proportions of patients reporting quality of life statuses ranging from "no problem" to "unable to/extreme problems" are shown.

The number of patients who were in the PRO population and answered at least one question on this questionnaire is also given $(n)$ 
respondents, respectively (Table 3). The weighted German index score [29] derived from the EQ-5D-5L questionnaire was high for both patient cohorts (a mean of 0.84 for dulaglutide and 0.83 for liraglutide). In the TROPHIES study, more than $50 \%$ of the patient population reported low scores (no problems) for four EQ-5D-5L dimensions: "mobility," "self-care," "usual activities," and "anxiety/depression" (Fig. 2). "Pain/discomfort" was the most frequent patient-reported dimension. More than $60 \%$ of patients experienced slight to severe pain or discomfort. An overall mean score of 68 out of 100, which is the best imaginable health state, was measured with the EQ-VAS (Table 3).
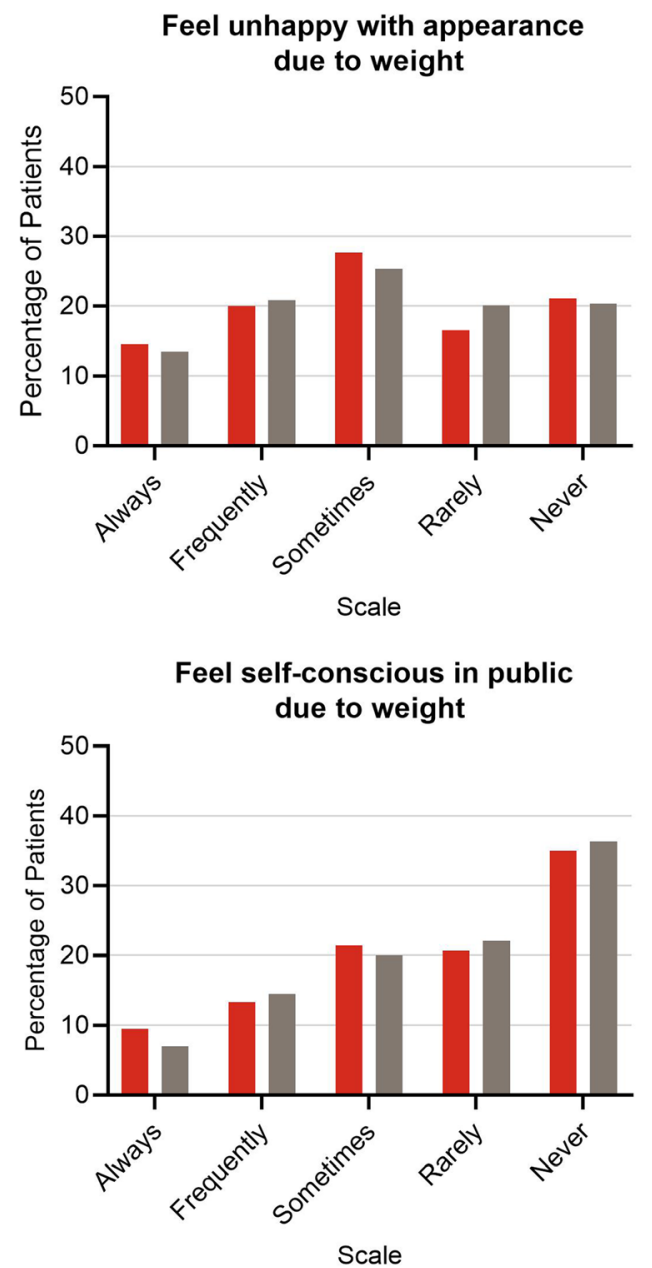

A total of 2108 respondents completed the IW-SP questionnaire (Table 3). The transformed scores were similar in the two cohorts (a mean of 60 for dulaglutide and 61 for liraglutide). In this assessment, one-third (approximately 35\%) of respondents reported that they always or frequently feel unhappy with their appearance due to their weight (Fig. 3). Half of respondents reported rarely or never feeling self-conscious in public due to their weight (approximately 57\%), and rarely or never feeling unhappy because they compared their weight with those of other people" (approximately 54\%).

The number of respondents who completed the DPM Life and Work Productivity sections was 2114 and 1292, respectively (Table 3). The

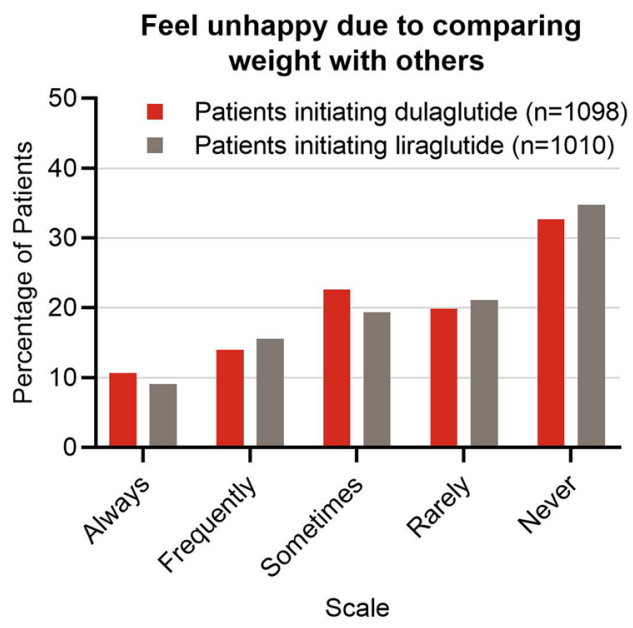

Fig. 3 Baseline results of the IW-SP questionnaire by item. The number of patients who, at this visit, were in the PRO population and answered at least one question on this questionnaire is given $(n)$ 

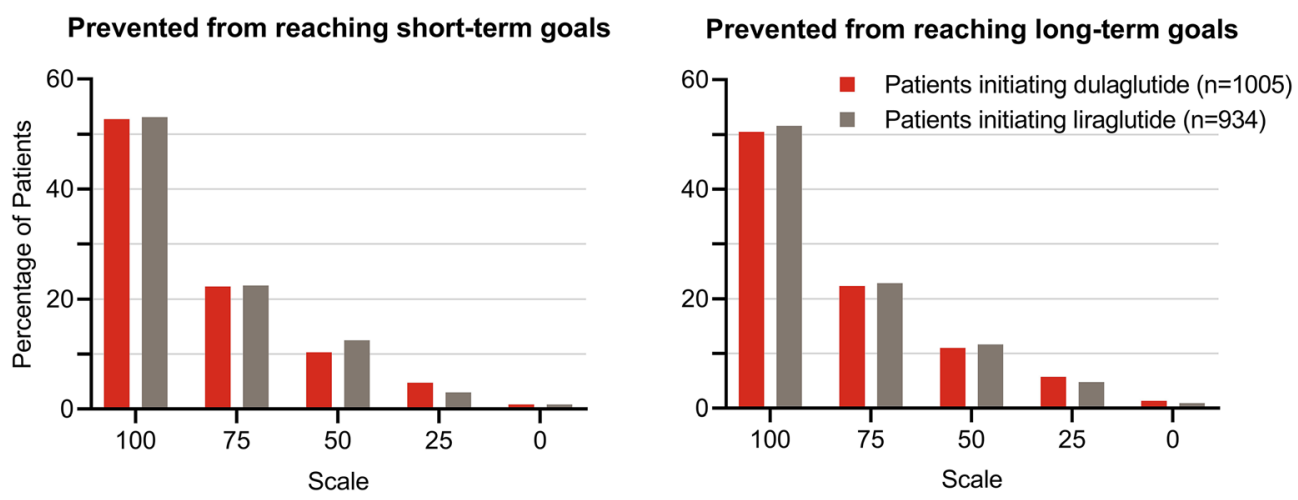

Fig. 4 The DPM short-term and long-term goal results at baseline, rated from 100 (not at all) to 0 (extremely). The number of patients who, at this visit, were in the PRO population and answered this question is given $(n)$

DPM scores were similar for the two cohorts. The work productivity scores were higher (87\%) than the life productivity scores (79\%). The mean (SD) score for the extent to which respondents felt that their diabetes prevented them from reaching their short-term and longterm goals was 84 (23) and 82 (24), respectively. More than $50 \%$ of patients reported no longterm or short-term goal impairments associated with T2DM (Fig. 4).

\section{DISCUSSION}

TROPHIES is a real-world observational study assessing the responses of T2DM patients initiating an injectable GLP-1 RA for the first time. The data described herein provide an overview of the clinical characteristics and information collected from the five PRO measures for patients who were enrolled in the study across France, Germany, and Italy. Other information regarding the TROPHIES study has been published previously $[18,19]$.

Overall, the patient demographics and characteristics were similar for both patient cohorts, except for the difference between the baseline and target HbA1c values and the number of patients with at least one macrovascular condition. Most patients had a high BMI, reflective of a largely obese study population, and inadequately controlled diabetes (the overall mean HbA1c was 8.2\%). These characteristics are similar to those reported in a previous study involving T2DM patients starting liraglutide treatment in a real-world clinical setting [11]. In the TROPHIES population, which had a mean diabetes duration of 8.5 years, HbA1c levels substantially exceeded the glycemic control targets set by physicians as their treatment objective, thereby supporting treatment intensification with GLP-1 RAs.

Treatment satisfaction is an important measure, as greater satisfaction is associated with better treatment compliance and improved persistence [30-32]. In this study, the DTSQs score of 25 out of 36 at baseline generally indicated moderate patient satisfaction with their current T2DM treatment prior to commencing the GLP-1 RA therapy. Patients initiating dulaglutide reported having less satisfaction with their current T2DM treatment than those initiating liraglutide. While the reasons for this difference are not known, the score for patients initiating dulaglutide was generally similar to that for patients initiating liraglutide. The DTSQs score indicated that there is potential to improve T2DM treatment satisfaction. This TROPHIES DTSQs baseline score is similar to what has previously been reported in other studies of T2DM patients before they started GLP-1 RA therapy [mean (SD) DTSQs score of 22.17 (7.64)] [11]. Of particular interest in this study is the mean score of 3.3 (out of 6.0) for the item regarding the time spent with unacceptably high blood glucose. The score indicated that patients perceived their hyperglycemic episode frequency was too high, consistent with a patient population in need of T2DM treatment intensification. 
The EQ-5D-5L and self-reported health status (VAS) at baseline provide insight into the reality of living with diabetes and diabetes treatment, as perceived by the patient. Depending on the inclusion criteria and sample size for the study, EQ-5D-5L scores reported in several studies of patients with T2DM tend to be in the range of $0.7-0.8[13,33,34]$. The mean EQ-5D-5L index score found in this study is in line with such findings and indicates a moderate-to-positive health status $[13,35]$. The EQ-VAS score, which indicates a moderate patient-rated health status, is also consistent with previously reported scores for patients with T2DM [34-36]. An assessment of the five individual EQ-5D-5L domains highlights the main challenges reported by patients: in this study, the majority of patients experienced problems with pain or discomfort, which explains why patients rated their health status as moderate according to the VAS scale.

Obesity is common among patients with T2DM. Obese patients with T2DM have been shown to more likely value weight loss than nonobese patients with T2DM [37]. Although published IW-SP data obtained in a real-world setting are limited, it is an important outcome in diabetes treatment [38]. In this TROPHIES study, moderate IW-SP scores were reported for both cohorts, indicating that patients were impacted by weight-related self-perceptions. The IW-SP indicated that the majority of patients were-at least sometimes-unhappy with their body weight, which is in line with previous descriptions of patients with T2DM in clinical trials [13]. This outcome is reasonable considering the high BMI [mean (SD) 33.9 (6.6) $\mathrm{kg} / \mathrm{m}^{2}$ ] reported for this study population at baseline.

Published DPM data is limited; therefore, the additional information regarding patient work and life productivity obtained in this study will provide valuable insights into how diabetes impacts patients [39-41]. Overall, the Work Productivity and Life Productivity scores reported for the TROPHIES participants were $87 \%$ and $79 \%$, respectively, and were similar to scores observed for patients facing T2DM treatment changes in a clinical trial setting [39]. Both this study and the previous clinical study showed that the work productivity scores were higher than the life productivity scores, perhaps indicating that T2DM impacts life productivity more than formal work productivity. The results from the standalone items on short-term and long-term goals showed that approximately $50 \%$ of study patients felt that diabetes did not impact their goals. The other 50\% felt that the disease did impact their goals to some extent (ranging from slightly to extremely).

\section{Limitations}

This study may suffer from multiple limitations. These include the trial design, as patients are from a nonrandomized real-life setting, with potential confounding factors. Moreover, the overall patient population of the study may not be fully representative of T2DM cohorts due to potential physician-related and health care system-related selection processes, which could differ between countries. Not all patients completed all of the questionnaires. Among all of the PRO measures considered in this study, the questions relating to the DPM Work Productivity measure were most likely to be overlooked by patients. It is unclear whether this was because respondents believed that this part of the DPM only applied to working participants or because participants were not willing to complete the second page of the questionnaire.

\section{CONCLUSION}

The information gained from PROs in observational studies is important for understanding treatment benefits within a real-world setting. Such studies also provide the opportunity to evaluate patients' perspectives in routine practice, which differs from a clinical trial setting. This diversified panel of both generic and disease-specific PRO instruments evaluated the perspectives of these real-world observational study T2DM patients who were starting GLP-1 RA therapy at the time of study enrollment. The data indicate that in clinical practice, patients with T2DM who need treatment intensification to improve glycemic control and who are initiating their first injectable therapy with either 
dulaglutide or liraglutide, generally reported similar health statuses and PROs at baseline. In this study, changes in the patient-reported outcomes over time will help us to understand patients' perspectives regarding their quality of life and other parameters after starting the new GLP-1 RA treatment regimen in this real-world setting.

\section{ACKNOWLEDGEMENTS}

The authors thank the participants, caregivers, and investigators at the study centers across France, Germany, and Italy. The authors are grateful to IQVIA for their help in the recruitment and the running of the TROPHIES study. The authors also thank Róise Ella McGovern PhD, of Eli Lilly and Company, for providing writing and editorial assistance.

Funding. This work and the journal's rapid service fee were funded by Eli Lilly and Company.

Authorship. All named authors meet the International Committee of Medical Journal Editors (ICMJE) criteria for authorship for this article, take responsibility for the integrity of the work as a whole, and have given their approval for this version to be published.

Author Contributions. KB, HS, LEGP, MR, $\mathrm{HJ}$, and $\mathrm{KN}$ designed the trial. UA, BG, FG, LEGP, MR, MOF, EH, and HJ were responsible for medical oversight during the trial. HS was responsible for the statistical considerations in the analysis and trial design. HS is the guarantor of this work and, as such, takes responsibility for the integrity of the data and the accuracy of the data analysis. All authors contributed to the design of this baseline analysis and helped to interpret the data and critically review the manuscript. All authors approved the final version of the manuscript and take full responsibility for the content.

Prior Presentation. The data from this study were presented in part at ISPOR Europe 2019, held November 2-6, 2016, in Copenhagen, Denmark.

Disclosures. Kristina Boye, Hélène Sapin, Luis-Emilio García-Pérez, Myriam Rosilio, Marco Orsini Federici, Elke Heitmann, Heike Jung, and Kirsi Norrbacka are full-time employees and shareholders of Eli Lilly and Company; Ulrich Aigner has no disclosures to declare. Francesco Giorgino (1) provides research support for Eli Lilly, Lifescan, and Takeda; (2) is a consultant for Boehringer Ingelheim, Lifescan, Merck Sharp \& Dohme, Sanofi, AstraZeneca, Medimmune, and Roche Diabetes Care; and (3) serves on the advisory boards for AstraZeneca, Eli Lilly, Novo Nordisk, Roche Diabetes Care, and Sanofi. Bruno Guerci (1) provides research support for Medtronic, Vitalaire, Sanofi, Eli Lilly, and Novo Nordisk; (2) a clinical investigator for Sanofi, Eli Lilly, NovoNordisk, GSK, BMS, AstraZeneca, Medtronic, Abbott, Roche Diagnostics, MSD, Novartis, Janssen, and Boehringer Ingelheim; and (3) serves as an advisory panel/board member for Sanofi, Eli Lilly, Novo Nordisk, Novartis, GSK, MSD, Boehringer Ingelheim, AstraZeneca, Abbott, Medtronic, and Roche Diagnostics.

Compliance With Ethics Guidelines. The study protocol was approved by local institutional review boards, and all patients provided written informed consent. The study is executed in accordance with the Declaration of Helsinki 1964 and its later amendments and the Guideline for Good Clinical Practice as well as country-specific requirements [28]. Eli Lilly \& Company received approval to carry out the study at each study site before study initiation.

Data Availability. The datasets analyzed during the current study are available from the corresponding author on reasonable request.

Open Access. This article is licensed under a Creative Commons Attribution-NonCommercial 4.0 International License, which permits any non-commercial use, sharing, adaptation, distribution and reproduction in any medium or format, as long as you give 
appropriate credit to the original author(s) and the source, provide a link to the Creative Commons licence, and indicate if changes were made. The images or other third party material in this article are included in the article's Creative Commons licence, unless indicated otherwise in a credit line to the material. If material is not included in the article's Creative Commons licence and your intended use is not permitted by statutory regulation or exceeds the permitted use, you will need to obtain permission directly from the copyright holder. To view a copy of this licence, visit http:// creativecommons.org/licenses/by-nc/4.0/.

\section{REFERENCES}

1. Davies MJ, D'Alessio DA, Fradkin J, et al. Management of hyperglycaemia in type 2 diabetes, 2018. A consensus report by the American Diabetes Association (ADA) and the European Association for the Study of Diabetes (EASD). Diabetologia. 2018;61(12):2461-98.

2. Davies MJ, D'Alessio DA, Fradkin J, et al. Management of hyperglycaemia in type 2 diabetes, 2018. A consensus report by the American Diabetes Association (ADA) and the European Association for the Study of Diabetes (EASD). Diabetes Care. 2018;41(12):2669-701.

3. American Diabetes Association. 9. Pharmacologic approaches to glycemic treatment. Standards of medical care in diabetes-2020. Diabetes Care. 2020;43(Supplement 1):S98-S110.

4. Feinglos MN, Saad MF, Pi-Sunyer FX, An B, Santiago O. Effects of liraglutide (NN2211), a long-acting GLP-1 analogue, on glycaemic control and bodyweight in subjects with type 2 diabetes. Diabet Med. 2005;22(8):1016-23.

5. Barrington P, Chien JY, Tibaldi F, et al. LY2189265, a long-acting glucagon-like peptide- 1 analogue, showed a dose-dependent effect on insulin secretion in healthy subjects. Diabetes Obes Metab. $2011 ; 13(5): 434-8$.

6. Barrington P, Chien JY, Showalter HD, et al. A 5-week study of the pharmacokinetics and pharmacodynamics of LY2189265, a novel, long-acting glucagon-like peptide- 1 analogue, in patients with type 2 diabetes. Diabetes Obes Metab. 2011;13(5):426-33.

7. Dungan KM, Povedano ST, Forst T, et al. Onceweekly dulaglutide versus once-daily liraglutide in metformin-treated patients with type 2 diabetes (AWARD-6): a randomised, open-label, phase 3, non-inferiority trial. Lancet. 2014;384(9951): 1349-57.

8. Anderson JE, Thieu VT, Boye KS, Hietpas RT, GarciaPerez LE. Dulaglutide in the treatment of adult type 2 diabetes: a perspective for primary care providers. Postgrad Med. 2016;128(8):810-21.

9. Gentilella R, Romera I, Nicolay C, et al. Change in $\mathrm{HbA1c}$ across the baseline HbA1c range in type 2 diabetes patients receiving once-weekly dulaglutide versus other incretin agents. Diabetes Ther. 2019;10(3):1113-25.

10. Reaney M, Mathieu C, Ostenson CG, et al. Patientreported outcomes among patients using exenatide twice daily or insulin in clinical practice in six European countries: the CHOICE prospective observational study. Health Qual Life Out. 2013;11: 217.

11. Gautier JF, Martinez L, Penfornis A, et al. Effectiveness and persistence with liraglutide among patients with type 2 diabetes in routine clinical practice-EVIDENCE: a prospective, 2-year followup, observational, post-marketing study. Adv Ther. 2015;32(9):838-53.

12. Yu M, Van Brunt K, Varnado OJ, Boye KS. Patientreported outcome results in patients with type 2 diabetes treated with once-weekly dulaglutide: data from the AWARD phase III clinical trial programme. Diabetes Obes Metab. 2016;18(4):419-24.

13. Yu M, Brunt KV, Milicevic Z, Varnado O, Boye KS. Patient-reported outcomes in patients with type 2 diabetes treated with dulaglutide added to titrated insulin glargine (AWARD-9). Clin Ther. 2017;39(11):2284-95.

14. Matza LS, Boye KS, Currie BM, et al. Patient perceptions of injection devices used with dulaglutide and liraglutide for treatment of type 2 diabetes. Curr Med Res Opin. 2018;34(8):1457-64.

15. Boye KS, Matza LS, Stewart KD, et al. Patient preferences and health state utilities associated with dulaglutide and semaglutide injection devices among patients with type 2 diabetes in Italy. J Med Econ. 2019;22(8):806-13.

16. Nauck MA, Buse JB, Mann JFE, et al. Health-related quality of life in people with type 2 diabetes participating in the LEADER trial. Diabetes Obes Metab. 2019;21(3):525-32.

17. Matza LS, Boye KS, Stewart KD, et al. Assessing patient PREFERence between the dulaglutide pen and the semaglutide pen: a crossover study (PREFER). Diabetes Obes Metab. 2020;22:355-64. 
18. García-Pérez LE, Sapin H, Norrbacka K, et al. PDB116 The real-world observational prospective study of health outcomes with dulaglutide and liraglutide in type 2 diabetes patients (TROPHIES): design and baseline characteristics. Value Health. 2019;22:S593.

19. Sapin H, García-Pérez LE, Norrbacka K, et al. PDB82 The real-world observational prospective study of health outcomes with dulaglutide and liraglutide in type 2 diabetes patients (TROPHIES): countryspecific characteristics. Value Health. 2019;22:S588.

20. European Medicines Agency. Trulicity: summary of product characteristics. 2019. https://www.ema. europa.eu/en/documents/product-information/ trulicity-epar-product-information_en.pdf.

21. European Medicines Agency. Victoza: summary of product characteristics. 2019. https://www.ema. europa.eu/documents/product-information/ victoza-epar-product-information_en.pdf.

22. Bradley C. Handbook of psychology and diabetes. A guide to psychological measurement in diabetes research and practice. 1st ed. Abingdon: Routledge; 1994 (formerly published by Harwood Academic Publishers).

23. Bradley C, Lewis KS. Measures of psychological well-being and treatment satisfaction developed from the responses of people with tablet-treated diabetes. Diabet Med. 1990;7(5):445-51.

24. Dolan P. Modeling valuations for EuroQol health states. Med Care. 1997;35(11):1095-108.

25. EuroQol Research Foundation. EQ-5D-5L user guide. 2019. https://euroqol.org/publications/userguides. Accessed 13 Mar 2020

26. Hayes RP, Nelson DR, Meldahl ML, Curtis BH. Ability to perform daily physical activities in individuals with type 2 diabetes and moderate obesity: a preliminary validation of the Impact of Weight on Activities of Daily Living Questionnaire. Diabetes Technol Ther. 2011;13(7):705-12.

27. Brod M, Skovlund SE, Wittrup-Jensen KU. Measuring the impact of diabetes through patient report of treatment satisfaction, productivity and symptom experience. Qual Life Res. 2006;15(3):481-91.

28. World Medical Association. Declaration of Helsinki. Recommendations guiding physicians in biomedical research involving human subjects. JAMA. 1997;277(11):925-6.

29. Ludwig K, Graf von der Schulenburg JM, Greiner W. German value set for the EQ-5D-5L. Pharmacoecon. 2018;36(6):663-74.
30. Revicki DA. Patient assessment of treatment satisfaction: methods and practical issues. Gut. 2004;53(Suppl 4):iv40-iv44.

31. Speight J. Assessing patient satisfaction: concepts, applications, and measurement. Value Health. 2005;8(s1):S6-S8.

32. Barbosa CD, Balp MM, Kulich K, Germain N, Rofail D. A literature review to explore the link between treatment satisfaction and adherence, compliance, and persistence. Patient Prefer Adherence. 2012;6:39-48.

33. Clarke P, Gray A, Holman R. Estimating utility values for health states of type 2 diabetic patients using the EQ-5D (UKPDS 62). Med Decis Making. 2002;22(4):340-9.

34. Redekop WK, Koopmanschap MA, Stolk RP, et al. Health-related quality of life and treatment satisfaction in Dutch patients with type 2 diabetes. Diabetes Care. 2002;25(3):458-63.

35. Bagust A, Beale S. Modelling EuroQol health-related utility values for diabetic complications from CODE-2 data. Health Econ. 2005;14(3):217-30.

36. Reaney M, Elash CA, Litcher-Kelly L. Patient reported outcomes (PROs) used in recent phase 3 trials for type 2 diabetes: a review of concepts assessed by these PROs and factors to consider when choosing a PRO for future trials. Diabetes Res Clin Pract. 2016;116:54-67.

37. Matza LS, Yurgin N, Boye KS, Malley K, Shorr JM. Obese versus non-obese patients with type 2 diabetes: patient-reported outcomes and utility of weight change. Curr Med Res Opin. 2007;23(9):2051-62.

38. Strizek A, Shalhoub H, Matza LS, et al. PDB112 Experiences of patients with type 2 diabetes mellitus in the kingdom of Saudi Arabia. Value Health. 2019;22:S593.

39. Meneghini L, Kesavadev J, Demissie M, Nazeri A, Hollander P. Once-daily initiation of basal insulin as add-on to metformin: a 26-week, randomized, treat-to-target trial comparing insulin detemir with insulin glargine in patients with type 2 diabetes. Diabetes Obes Metab. 2013;15(8):729-36.

40. Kaneko S, Chow F, Choi DS, et al. Insulin degludec/ insulin aspart versus biphasic insulin aspart 30 in Asian patients with type 2 diabetes inadequately controlled on basal or pre-/self-mixed insulin: A 26-week, randomised, treat-to-target trial. Diabetes Res Clin Pract. 2015;107(1):139-47.

41. Thiyagarajan S, John S. Does diabetes blight work productivity: a cross-sectional investigation on selected type 2 diabetes participants. J Soc Health Diab. 2017;5(1):43-6. 